\title{
Nickel/Porous Carbon Composite Derived from Bimetallic MOFs for Electrical Double-Layer Supercapacitor Application
}

\author{
XianHe Meng ${ }^{1}$, ChuBin $\mathrm{Wan}^{1}$, SuYe Yu ${ }^{1}$, XiaoPing Jiang ${ }^{2}$, Xin Ju ${ }^{1, *}$ \\ ${ }^{1}$ Department of Physics, University of Science and technology Beijing, Beijing, P. R. China \\ ${ }^{2}$ Shandong Key Laboratory for High Strength Lightweight Metallic Materials, Advanced Materials \\ Institute, Shandong Academy of Sciences, Jinan 250014, P. R. China \\ *E-mail: jux@ustb.edu.cn
}

doi: $10.20964 / 2018.08 .49$

Received: 11 April 2018 / Accepted: 8 June 2018 / Published: 5 July 2018

\begin{abstract}
A novel method to synthesize nickel/ porous activated carbon composite materials has been proposed initially from bimetallic Ni(II)-MOF-5s. Electrochemical results present that the nickel /activated carbon maintains nearly $83 \%$ capacity with the current density increases from 0.2 to $50 \mathrm{~A} \mathrm{~g}^{-1}$ and shows excellent cyclic stability of about $1.5 \%$ decrease after 5000 cycles. This product also demonstrated a good rectangularity at a high scan voltage of $2 \mathrm{~V} \mathrm{~s}^{-1}$ and very low charge transfer resistance of approximately $0.35 \Omega$, which can be a prospective electrode material for electrochemical double-layer supercapacitor applications.
\end{abstract}

Keywords: Bimetallic MOFs; Ni nanoparticles; Graphitic porous carbon; Supercapacitor

\section{$\underline{\text { FULL TEXT }}$}

(C) 2018 The Authors. Published by ESG (www.electrochemsci.org). This article is an open access article distributed under the terms and conditions of the Creative Commons Attribution license (http://creativecommons.org/licenses/by/4.0/). 